\title{
Schwann cell hyperplasia and tumors in transgenic mice expressing a naturally occurring mutant NF2 protein
}

\author{
Marco Giovannini, ${ }^{1,2,3}$ Els Robanus-Maandag, ${ }^{3}$ Michiko Niwa-Kawakita, ${ }^{1,2}$ Martin van der Valk, ${ }^{3}$ \\ James M. Woodruff, ${ }^{4}$ Laurence Goutebroze, ${ }^{1,2}$ Philippe Mérel, ${ }^{1,3}$ Anton Berns, ${ }^{3}$ \\ and Gilles Thomas ${ }^{1,2,5}$

\begin{abstract}
${ }^{1}$ Institut National de la Santé et de la Recherche Médicale (INSERM) U434-Institut Curie, 75005 Paris, France; ${ }^{2}$ Centre d'Etude du Polymorphisme Humain (CEPH) Fondation Jean Dausset, 75010 Paris, France; ${ }^{3}$ Division of Molecular Genetics and Centre for Biomedical Genetics, The Netherlands Cancer Institute, 1066 CX Amsterdam, The Netherlands;

${ }^{4}$ Department of Pathology, Memorial Sloan-Kettering Cancer Center, New York, New York 10021 USA
\end{abstract}

\begin{abstract}
Specific mutations in some tumor suppressor genes such as p53 can act in a dominant fashion. We tested whether this mechanism may also apply for the neurofibromatosis type-2 gene (NF2) which, when mutated, leads to schwannoma development. Transgenic mice were generated that express, in Schwann cells, mutant NF2 proteins prototypic of natural mutants observed in humans. Mice expressing a NF2 protein with an interstitial deletion in the amino-terminal domain showed high prevalence of Schwann cell-derived tumors and Schwann cell hyperplasia, whereas those expressing a carboxy-terminally truncated protein were normal. Our results indicate that a subset of mutant NF2 alleles observed in patients may encode products with dominant properties when overexpressed in specific cell lineages.
\end{abstract}

[Key Words: Neurofibromatosis type 2; schwannomin; Schwann cell tumors; tumor suppressor gene; dominant mutant; transgenic mice]

Received October 20, 1998; revised version accepted February 25, 1999.

Neurofibromatosis type 2 (NF2) is an inherited condition, characterized primarily by an increased susceptibility to develop multiple schwannomas and meningiomas (Eldridge 1981). It is associated with germ-line mutations in the NF2 gene that are predicted to lead to major structural impairment of its product, schwannomin (Rouleau et al. 1993) or merlin (Trofatter et al. 1993). Both sporadic and familial schwannomas frequently show biallelic inactivation of the NF2 gene, thus meeting the criteria usually required for a tumor suppressor gene (Bianchi et al. 1994; Bijlsma et al. 1994; Sainz et al. 1994; Twist et al. 1994; Merel et al. 1995b; Jacoby et al. 1996). In contrast to the narrow spectrum of benign tumors observed in human NF2 patients, Nf2 heterozygous mutant $\left(\mathrm{Nf2}^{+/-}\right)$ mice develop a variety of highly metastatic tumors, mainly osteosarcomas (McClatchey et al. 1998). Nearly all of these tumors exhibit loss of the wild-type Nf2 allele indicating that also in the mouse the Nf2 gene acts as a classical tumor suppressor gene. Remarkably, however, the $\mathrm{Nf2}^{+/-}$mice do not develop schwannomas, the hallmark tumors associated with human NF2.

Two major isoforms of the NF2 gene product are generated by alternative splicing and differ in their carboxyl

${ }^{5}$ Corresponding author.

E-MAIL thomas@cephb.fr; FAX 33153725151. terminus. Schwannomin isoform 1 is a 595 amino acid protein (Rouleau et al. 1993) composed of two interacting structural domains, the amino and carboxyl terminus (Sherman et al. 1997; Gutmann et al. 1998). Schwannomin isoform 2 (590 amino acids) contains 11 strongly hydrophilic amino acids at its carboxyl terminus and does not self associate (Sherman et al. 1997). It has been suggested that this intramolecular interaction (closed conformation) is essential for tumor suppressor activity, whereas failure to form such a self-folded complex results in an inactive protein (open conformation) (Sherman et al. 1997; Xu and Gutmann 1998). When transiently expressed in various cell types, mutant proteins corresponding to naturally occurring NF2 mutations demonstrate alternate localizations (Deguen et al. 1998, unpubl.; Shaw et al. 1998a; Xu et al. 1998). Carboxy-terminal deletion mutants of various lengths remain located at the cell membrane. In contrast, mutants with an intact carboxy-terminal domain but with a deleted or altered amino-terminal domain are delocalized mainly in the perinuclear cytoplasmic region. Such delocalization was observed for a mutant protein modeled from naturally occurring mutations in which exons 2-3 are spliced out without frameshift, Sch- $\Delta(39-121)$ (Deguen et al. 1998).

To develop a system by which to identify functional 
domains of the NF2 protein that may play a role in oncogenesis, we have generated transgenic mice expressing, under the control of the Schwann cell-specific P0 promoter (Messing et al. 1992), either a mutant schwannomin modeled from a naturally occurring mutation, Sch- $\Delta(39-121)$, or a schwannomin prototypic for carboxy-terminal deletion mutants, Sch- $\Delta$ Cter.

\section{Results}

Transgenic mice were generated with DNA constructs in which human cDNAs encoding either Sch- $\Delta$ Cter or isoform 1 of Sch- $\Delta(39-121)$ were placed under the control of the minimal P0 promoter (Fig. 1A). The P0 protein is the major structural protein of peripheral myelin, and previous studies identified regulatory elements within $1.1 \mathrm{~kb}$ of the proximal $5^{\prime}$-flanking DNA that were suffi- cient to direct appropriate Schwann cell-specific expression of heterologous genes in transgenic mice (Messing et al. 1992). To detect transgene-specific expression, the mutant proteins were tagged with the VSV epitope (Kreis 1986). Such addition leaves unaltered the subcellular localization of the wild-type and mutant schwannomins (Deguen et al. 1998). Strains that expressed the 39-kD (Sch- $\Delta$ Cter) or $62-\mathrm{kD}$ [Sch- $\Delta(39-121)]$ mutant schwannomins in peripheral nerves were identified by immunoblotting with a polyclonal anti-NF2-Nter (Fig. 1B). The transgenic nature of both proteins was confirmed by immunoblotting with anti-VSV polyclonal antibodies (Fig. 1C). Additional tissues of one P0-Sch$\Delta$ Cter and three P0-Sch- $\Delta(39-121)$ strains were also analyzed (Fig. 1C). As expected, no expression was observed in heart, spleen, lung, kidney, liver and in various structures of the central nervous system such as brain, cer-

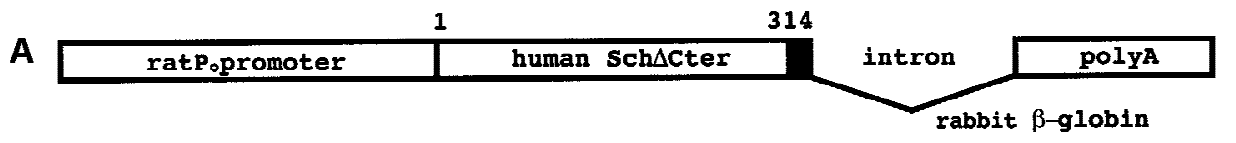

$200 \mathrm{bp}$

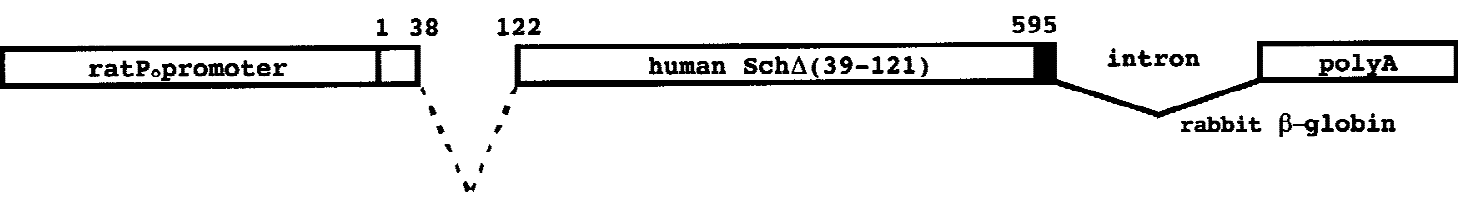

B

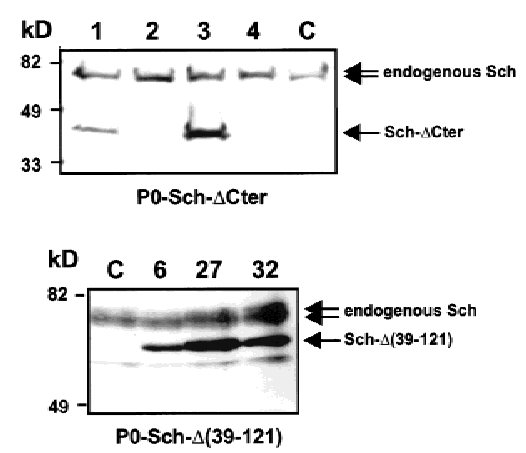

C

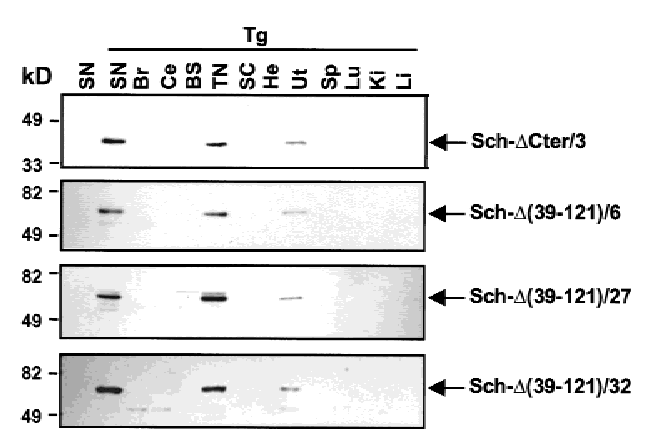

Figure 1. Structure and expression of the transgenes. (A) Schematic representation of the P0-Sch- $\Delta$ Cter and P0-Sch- $\Delta(39-121)$ transgenes. The transgenic constructs were made by inserting the VSV-tagged (black box) mutated human NF2 cDNAs into plasmid pPG6 between the $5^{\prime}$ flanking sequence from the rat $P 0$ gene $(1.1 \mathrm{~kb})$ and the rabbit $\beta$-globin $3^{\prime}$ splicing plus polyadenylation signal $(1.2 \mathrm{~kb})$. (B) Transgene expression analysis by Western blotting. The $39-\mathrm{kD}$ (Sch- $\Delta$ Cter) and $62-\mathrm{kD}$ Sch- $\Delta(39-121)$ schwannomin mutants were detected by immunoblotting with a polyclonal anti-NF2-Nter serum in protein extracts from sciatic nerve of the $\mathrm{F}_{1}$ mice of two of four P0-Sch- $\Delta$ Cter and three of three P0-Sch- $\Delta(39-121)$ independent strains. The polyclonal anti-NF2-Nter A-19, raised against a peptide corresponding to amino acids 2-21 of human schwannomin, detects both the endogenous murine NF2 protein and the two transgenic mutant human schwannomins (arrows). (Lanes 1-4) Sciatic nerves from strains P0-Sch- $\Delta$ Cter; (lanes 6,27,32) sciatic nerves from strains P0-Sch- $\Delta(39-121)$. (C) Sciatic nerves from nontransgenic FVB/N littermate. $(C)$ To confirm that the mutant proteins are encoded by the transgene and to analyze the spatial profile of expression of the transgenes, total protein extracts were obtained from various organs of transgenic animals of strains P0-Sch- $\Delta$ Cter/3 and P0-Sch- $\Delta(39-121) / 6,27$, and 32 and analyzed by Western blotting. Transgenic proteins were readily detected by immunoblotting with anti-VSV polyclonal antibodies in peripheral nerves (trigeminal and sciatic nerves) and uterus. (SN) Sciatic nerve; (Br) brain; (Ce) cerebellum; (BS) brain stem; (TN) trigeminal nerve; (SC) spinal cord; (He) heart; (Ut) uterus; (Sp) spleen; (Lu) lung; (Ki) kidney; (Li) liver. 
ebellum, optic nerve, and spinal cord. However, a low level of expression was consistently detected in the uterus, which shows rich innervation (Moscarini et al. 1982; Houdeau et al. 1998).

A total of 36 P0-Sch- $\Delta$ Cter (lines 1 and 3 ) and 36 P0Sch- $\Delta(39-121)$ (lines 6, 25, 27, and 32; see Table 1) transgenic mice was kept under observation for the appearance of abnormal phenotypes over a period of 24 months. P0-Sch- $\Delta$ Cter transgenic mice showed a survival rate similar to that of nontransgenic littermates. Despite high expression of the Sch- $\Delta$ Cter transgene in peripheral nerves and uterus, these structures appeared normal and not prone to tumor development. In agreement with the known spontaneous tumor profile of aging FVB/N mice (Mahler et al. 1996), various tumors were identified in these mice. In total, 12 lung adenocarcinomas, 2 pituitary adenomas (in females with reactive mammary adenocarcinomas), 2 sarcomas of the subcutis, and 1 histiocytic sarcoma were found. None of these tumors expressed the transgene to a detectable level as determined by immunoblotting. The sole exception was a mammary adenocarcinoma that showed weak expression of the transgene when compared with the endogenous schwannomin level. The microscopic analysis of the tumor revealed nerve bundles that are probably responsible for this weak expression level (data not shown).

In contrast to P0-Sch- $\Delta$ Cter transgenic mice, P0-Sch$\Delta(39-121)$ mutant mice showed a decreased survival rate (Kaplan-Meier test: $P=0.0001)$. The average age of tumor incidence in P0-Sch- $\Delta(39-121)$ transgenic mice was 17.5 months, with tumors detected between 9 and 20 months. Fifteen peripheral nerve tumors were found in 12 of 36 mice of the four independent lines from 9 months on (Table 1). Four of these tumors originated unambiguously from the trigeminal nerve and spinal ganglia (Fig. 2a,d). Their Schwann cell origin was confirmed by strong immunoreactivity with S-100 protein and the $75-\mathrm{kD}$ low affinity nerve growth factor receptor (LNGFR) (Fig. 2b,c). The S-100 protein is expressed during the later stages of Schwann cell differentiation (Zorick and Lemke 1996) and is also present in rather differentiated neoplastic Schwann cells (Walker et al.
1994). High levels of LNGFR expression are present in neural crest cells, Schwann cell precursors, and committed Schwann cells and its expression is down-regulated during the later stages of Schwann cell differentiation (Zorick and Lemke 1996). Accordingly, LNGFR is frequently expressed in neural crest-derived tumors of the peripheral nervous system, regardless of their degree of differentiation (Perosio and Brooks 1988; Hoshi et al. 1994). Tumors were found in the uterus of 8 of 20 female transgenic mice between the age of 13 and 20.5 months, all with similar histological features of interlacing fascicles of spindle-shaped cells showing areas of palisaded nuclei and ropelike formations resembling Verocay bodies (Fig. 2e). These features are suggestive of Schwann cell differentiation. To investigate further the histological origin of the uterine tumors, immunohistochemical detection of S-100 protein and LNGFR was performed. As summarized in Table 1, five of eight uterine tumors displayed areas of weak S-100 protein immunoreactivity (Fig. 2f), and eight of eight revealed a diffuse strong LNGFR immunoreactivity, which suggests their Schwann-cell origin (Fig. 2g). Other tumors showing strong LNGFR immunoreactivity were microscopically detected in the shorter curvature of the stomach, in the intestine, and in the pancreas of P0-Sch- $\Delta(39-121)$ transgenic mice (Fig. $2 \mathrm{~h}-\mathrm{j}$ ). In contrast to the intestinal and pancreatic spindle-cell tumors that showed areas of faint S-100 protein immunoreactivity, the tumor in the stomach displayed strong positivity for S-100 protein (Table 1). In addition to the transgene-related tumors, the 36 P0-Sch- $\Delta(39-121)$ mice developed a total of 11 lung tumors and 3 sarcomas. The latter were found unrelated to transgene expression (data not shown) and are seen in $5 \%$ of aging FVB/ $\mathrm{N}$ mice (Mahler et al. 1996).

Whenever possible, the expression of wild-type and mutant NF2 protein was monitored in fresh tumor samples by immunoprecipitation with a polyclonal antibody anti-NF2-Cter followed by immunoblotting analysis either with anti-NF2-Nter polyclonal antiserum or with a monoclonal anti-VSV-G antibody. The two polyclonal NF2 antisera directed at two distinct peptide epitopes have been shown to specifically immuno-

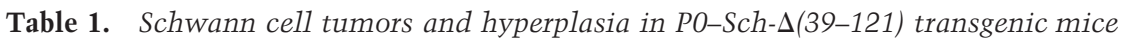

\begin{tabular}{|c|c|c|c|c|c|c|c|c|}
\hline \multirow[b]{2}{*}{ Tumor site } & \multirow[b]{2}{*}{$\begin{array}{c}\text { Line } \\
N(\mathrm{~F}: \mathrm{M})\end{array}$} & \multicolumn{5}{|c|}{ P0-Sch- $\Delta(39-121)(\mathrm{n}=44$ mice $)$} & \multirow[b]{2}{*}{ IHC $\alpha$-LNGFR } & \multirow[b]{2}{*}{ IHC $\alpha-S-100$} \\
\hline & & $\begin{array}{c}6 ; N f 2^{+/+} \\
6(3: 3)\end{array}$ & $\begin{array}{c}25 ; N f 2^{+/+} \\
3(2: 1)\end{array}$ & $\begin{array}{r}27 ; N f 2^{+/+} \\
15(10: 5)\end{array}$ & $\begin{array}{c}32 ; N f 2^{+/+} \\
12(5: 7)\end{array}$ & $\begin{array}{c}32 ; N f 2^{+/-} \\
8(7: 1)\end{array}$ & & \\
\hline Trigeminal $\mathrm{n}$. & & $0 / 6$ & $0 / 3$ & $0 / 15$ & $1 / 12$ & $0 / 8$ & $+1 / 1$ & $+1 / 1$ \\
\hline Spinal ganglia & & $0 / 6$ & $1 / 3$ & $2 / 15$ & $0 / 12$ & $0 / 8$ & N.D. & $+1 / 1$ \\
\hline Uterus & & $1 / 3$ & $0 / 2$ & $7 / 10$ & $0 / 5$ & $2 / 7$ & $+8 / 8$ & $+5 / 8$ \\
\hline Stomach & & $0 / 6$ & $0 / 3$ & $0 / 15$ & $1 / 12$ & $0 / 8$ & $+1 / 12$ & $+1 / 12$ \\
\hline Intestine & & $0 / 6$ & $0 / 3$ & $1 / 15$ & $0 / 12$ & $1 / 8$ & $+1 / 1$ & $+/-1 / 1$ \\
\hline Pancreas & & $0 / 6$ & $0 / 3$ & $1 / 15$ & $0 / 15$ & $0 / 8$ & $+1 / 1$ & $+/-1 / 1$ \\
\hline
\end{tabular}

Schwann cell hyperplasia

Spinal ganglia and/or muscle

$3 / 6$

$3 / 3$

$13 / 15$

$1 / 12$

$4 / 8$

N.D.

$+1 / 1^{\mathrm{a}}$

(IHC) Immunohystochemistry; (N.D.) not determined.

asee Fig. 5. 


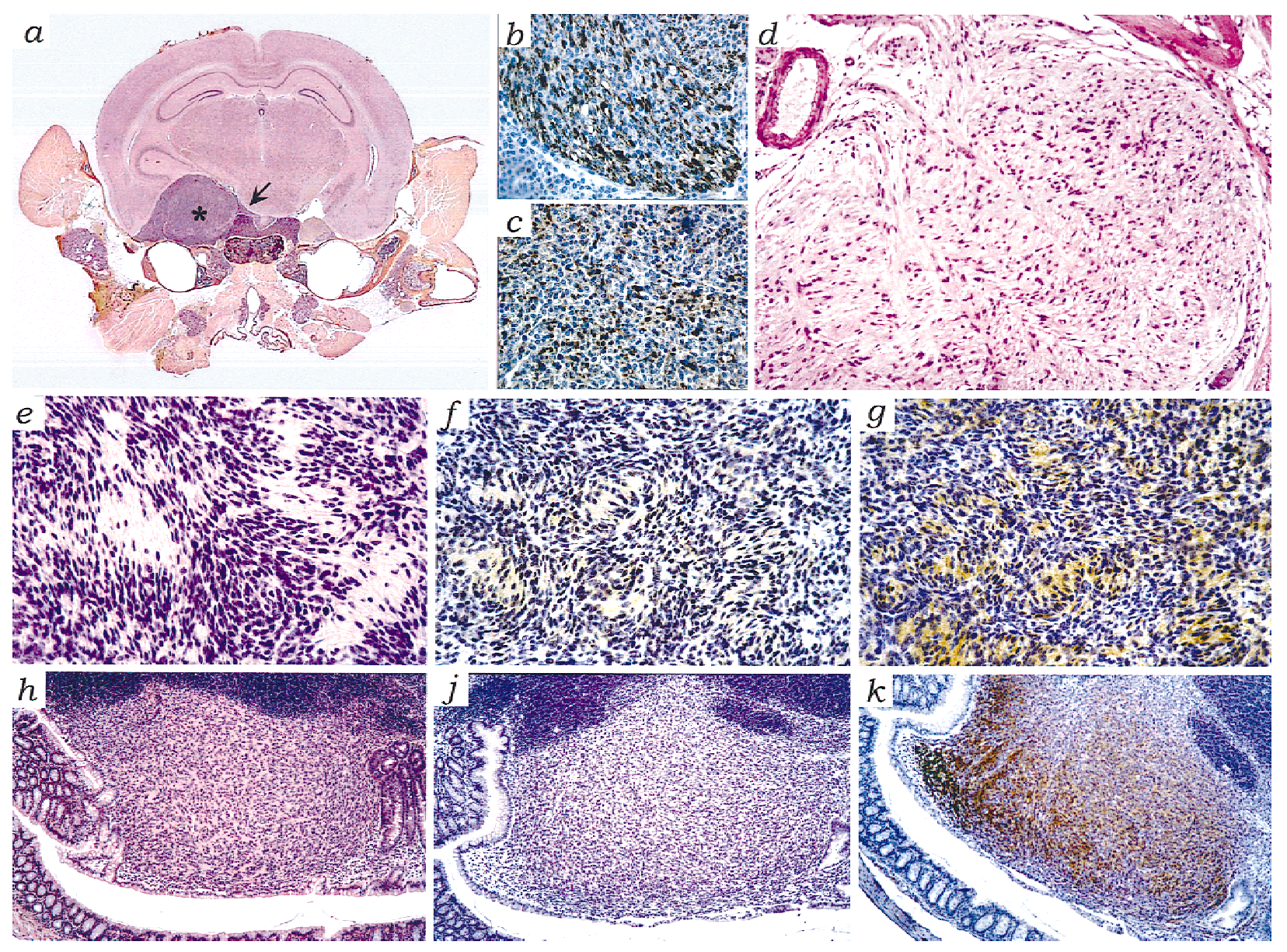

Figure 2. Schwann cell tumors in P0-Sch- $\Delta(39-121)$ transgenic mice. (a) Moderately proliferative and locally aggressive schwannoma (asterisk) originating from the ganglion semilunaris of the trigeminal nerve that had infiltrated peripherally the perineurium reaching the pituitary stalk (arrow) and invaded the surrounding soft tissues down to the region of the soft palate and the external ear region (9-month-old male, strain 32), hematoxylin and eosin stain. The tumor displayed moderate pleiomorphism, dense cellularity, and areas of S-100 $(b)$ protein and LNGFR immunoreactivity $(c)$. (d) Schwannoma arising from a paravertebral spinal ganglion in a 17-month-old mouse (strain 27) that presented a generalized increase in Schwann cells in various ganglia. The tumor was composed of loosely arranged interwoven bundles of fusiform cells within scant fibrovascular stroma. Tumor cells had indistinct borders and the cytoplasm blended into the stroma, hematoxylin and eosin. (e) Representative microscopic features of a uterine tumor. Compactly arranged spindle-shaped cells in tumor 4228 (17-month-old female; strain 6), hematoxylin and eosin stain. (f) Focal areas of weak S-100 protein and $(g)$ strong, diffuse LNGFR immunoreactivity in uterine tumor 4235 (20-month-old female; strain 27). (h) Schwann cell proliferation at the internal surface of a Peyer's plaque in a 20-month-old female (strain 27), hematoxylin and eosin stain, showing (j) weak S-100 protein, and $(k)$ strong LNGFR immunoreactivity. Magnification, $25 \times(a) ; 200 \times(b, c) ; 100 \times(d) ; 400 \times(e-g) ; 100 \times(h-k)$.

precipitate schwannomin (Shaw et al. 1998b). Expression of the transgenic protein was readily detectable in all uterine tumors under conditions that hardly allow detection of the Sch- $\Delta(39-121)$ in the normal transgenic uterus (Fig. 3). Also wild-type schwannomin could be detected in all of these tumors appearing as a doublet due to differential phosphorylation (Shaw et al. 1998b). The doublet observed around $62 \mathrm{kD}$ for Sch- $\Delta(39-121)$ with both anti-NF2-Nter and anti-VSV-G antibodies (Fig. 3) may also be due to differential phosphorylation. As for the peripheral nerve tumors of which no fresh material was available for protein analysis, interphase cytogenetic analysis on paraffin-embedded tissues was performed by fluorescent in situ hybridization (FISH) to confirm that both chromosomes 11 with wild-type $N f 2$ alleles were present. Because loss of an entire chromosome is a relatively frequent event during mouse tumorigenesis (Luongo et al. 1994), we utilized a mouse chromosome 11-specific probe. A strong FISH signal was obtained in two peripheral nerve tumors and in one uterine tumor with preservation of acceptable nuclear, cytoplasmic, and tissue morphology (Fig. 4). In all three cases, $~ 85 \%$ of the nuclei showed two hybridization signals, indicating that the tumor cells contained two copies of chromosome 11. As a result of nuclear truncation, the remaining nuclei showed one hybridization signal. Altogether, these data demonstrate that mutant schwannomin Sch$\Delta(39-121)$ has a true dominant effect.

In 13 of 36 mice (Table 1), microscopic foci of Schwann cell proliferation, schwannosis, were observed in various 


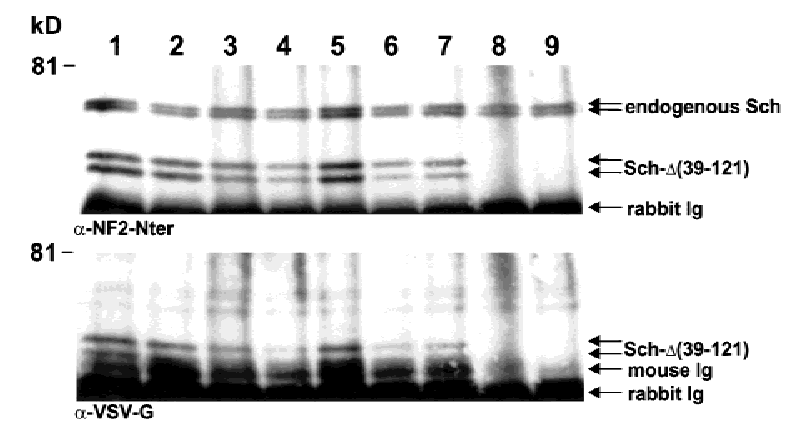

Figure 3. P0-Sch- $\Delta(39-121)$ transgene expression in tumors. Immunoprecipitations were performed on RIPA extracts of the different tumors with polyclonal antibody anti-NF2-Cter C-18. Immunoprecipitated proteins were separated on a $8 \%$ polyacrylamide gel and electrotransferred to nitrocellulose membrane. Immunoblottings were performed with anti-NF2-Nter A-19 polyclonal antibody (top) and anti-VSV-G monoclonal antibody (bottom). Detection was performed by chemoluminescence and the exposure time was defined for optimal detection of transgene expression in uterine tumors (lanes 1-7). Under these conditions, transgene expression in the normal transgenic uterus (lane 9) is hardly detectable. (Lane 1) Uterine tumor (strain 6); (lanes 2-7) uterine tumors (strain 27); (lane 8), lung adenocarcinoma (strain 27); (lane 9) normal transgenic uterus (strain 32).

spinal ganglia (Fig. 5a-c). As for human NF2 patients (Wiestler and Radner 1994), these foci most likely represent precursor lesions with the potential for progression into schwannomas. Schwannosis was also found in skeletal muscles in which hypertrophic nerve bundles showed Schwann cell hyperplasia (18 of 36 mice) (Fig. $5 \mathrm{~d}-\mathrm{f})$. Paravertebral, quadriceps, and intercostal muscles were most frequently involved. Schwannosis was detected in muscle and spinal ganglia as early as 6 and 9 months, respectively. In total, $53 \%$ of the P0-Sch- $\Delta(39$ 121) mice showed diffuse schwannosis, a phenotype completely absent in P0-Sch- $\Delta$ Cter mice. Transgenic line 27 (15 mice analyzed) showed the highest incidence of schwannosis in spinal ganglia and muscle with $86 \%$ of the mice presenting schwannosis in one or both locations (Table 1).

The finding of schwannosis in the spinal ganglia of 13 of 36 Sch- $\Delta(39-121)$ mice and spinal ganglion tumors in only 3 , indicates that additional events may be necessary for the full development of schwannomas. Nevertheless, the overall tumor incidence may be underestimated because of the small volume of the slow-growing lesions that are not associated with macroscopical changes.

To investigate further the genetic basis of the dominant effect observed for Sch- $\Delta(39-121)$, we crossed the P0-Sch- $\Delta(39-121)$ transgenic mice of line 32 with heterozygous Nf2 mutant mice. The latter mice, generated by homologous recombination in ES cells (M. Giovannini, E. Robanus-Maandag, M. Van der Valk, M. NiwaKawakita, V. Abramowski, L. Goutebroze, J.A. Woodruff, A. Berns, and G. Thomas, in prep.), do not show schwannosis or Schwann cell tumors, a finding similar to that in $\mathrm{Nf}^{+/-}$mice described by McClatchey et al. (1998). The P0-Sch- $\Delta(39-121)^{32}$ line was chosen because it exhibited the lowest percentage of schwannosis (Table 1) and no Schwann cell tumors of the uterus. Although the survival rate of $\mathrm{P} 0-\mathrm{Sch}-\Delta(39-121)^{32} ; N f 2^{+/-}(n=12)$ was similar to that of P0-Sch- $\Delta(39-121)^{32} N f 2^{+/+}(n=10)$ mice within a follow-up period of 28 months (data not shown), schwannosis and Schwann cell tumors were detected in 4 and 3 of 8 analyzed P0-Sch- $\Delta(39-$ $121)^{32} ; N_{f 2}{ }^{+/-}$mice, respectively, but only in 1 and 2 of 12 $\mathrm{PO}-\mathrm{Sch}-\Delta(39-121)^{32} ; \mathrm{Nf2^{+/+ }}$ mice, respectively. These results suggest that the tumorigenic activity of Sch- $\Delta(39-$ 121 ) is modulated by the number of functional Nf2 alleles in vivo, thus supporting the hypothesis that this dominant mutant negatively interferes with the NF2 tumor suppressor pathway.

\section{Discussion}

In humans, specific mutations in some tumor suppressor genes such as $p 53$ can act in a dominant-negative fashion (Nigro et al. 1989). Such mutations usually provide the cell with a selective advantage without the requirement of loss of the remaining functional allele. We show here that this mechanism may also apply to the NF2 gene in an experimental model. Promotion of Schwann cell tumorigenesis and schwannosis by Sch- $\Delta(39-121)$ modulated by the number of functional $N f 2$ alleles strongly
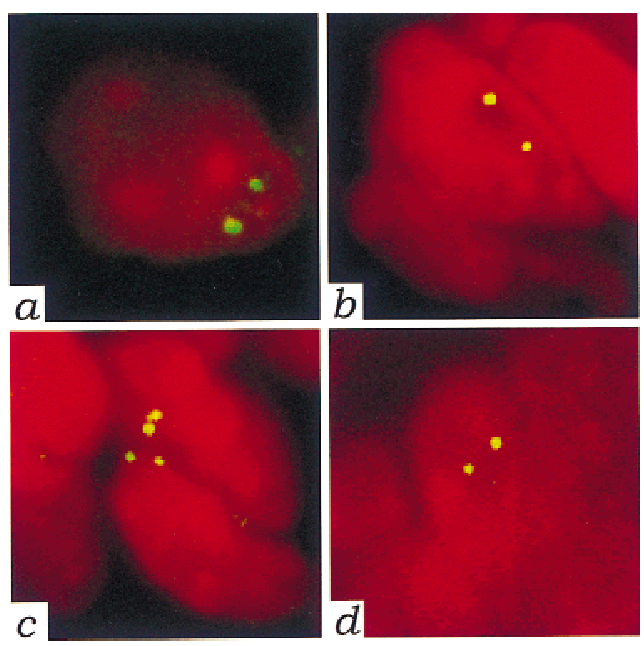

Figure 4. Tumors from P0-Sch- $\Delta(39-121)$ transgenic mice are diploid. FISH with mouse chromosome 11-specific probe on paraffin sections. The biotin-labeled probe was detected with FITCavidin and nuclei were visualized by counterstaining with propidium iodide. Nuclei from a normal trigeminal nerve $(a)$ and from a uterine tumor $(b)$ in which expression of wild-type schwannomin was shown by immunoprecipitation analysis (same tumor as in Fig. 3, lane 1), were taken as reference. The presence of two distinct hybridization signals in the majority of the hybridized nuclei from both tumor and normal tissue proved that the tumor was diploid for chromosome 11. Nuclei showing two distinct hybridization signals $(c)$ in a schwannoma originating from the trigeminal nerve of a transgenic P0-Sch$\Delta(39-121)$ mouse (same tumor as in Fig. 2A), and in a schwannoma arising from a paravertebral spinal ganglion $(d)$ (same tumor as in Fig. 2D). Magnification, 1250x. 


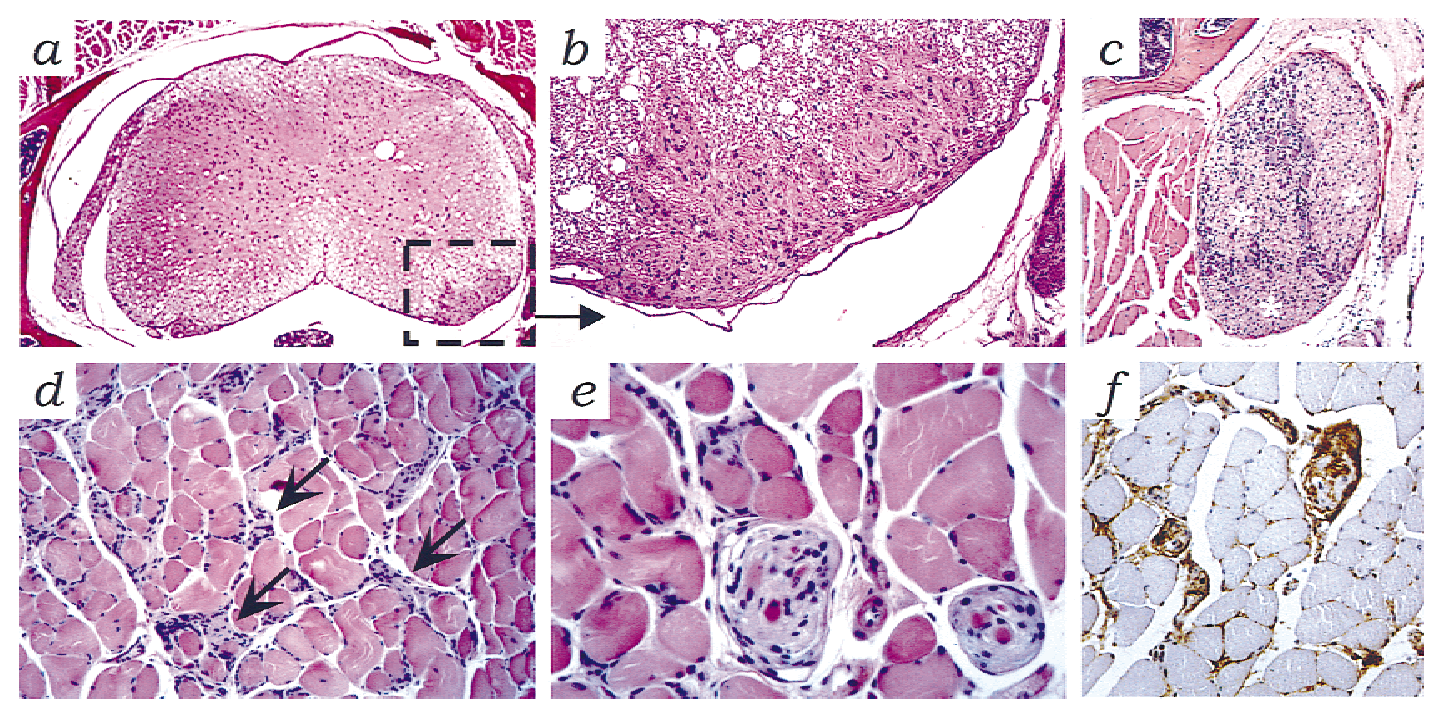

Figure 5. Schwannosis in P0-Sch- $\Delta(39-121)$ transgenic tissues. (a) Microscopic foci of proliferated Schwann cells (schwannosis) in the spinal cord [inset; enlarged in $b$ and $c$ (asterisks)] in a spinal ganglion. (d) Hyperplastic Schwann cells and hypertrophic nerve bundles (arrows) in skeletal muscle with (e) focal aspects of nodular Schwann cell growth displaying (f) S-100 protein immunoreactivity. Schwannosis is a frequent histopathological feature of the peripheral nerves of NF2 patients (Wiestler and Radner 1994). Hematoxylin and eosin stain. Magnification, $25 \times(a) ; 200 \times(b, d, f) ; 100 \times(c) ; 400 \times(e)$.

argues for a dominant function of this mutant protein. Koga et al. (1998) have recently shown that nuclear microinjection of a mutant NF2 cDNA lacking exon 2 sequences induces loss of cell adhesion in VA13 cells. These results indicate that exon-skipping mutations in the amino terminus of schwannomin cause a dominant effect on cell attachment. However, this experimental approach has not discriminated between a dominantnegative role or a dominant gain of function for this mutant NF2 allele. Nevertheless, in Drosophila a true dominant-negative NF2 mutant has been identified that causes overproliferation when expressed ectopically in the wing. The mutant carries an interstitial $\mathrm{N}$-ter deletion of seven amino acids that are identical in human (amino acids 177-183) and Drosophila NF2 and functional studies have shown that it interferes directly with the activity of the wild-type protein (LaJeunesse et al. 1998). We show here that Sch- $\Delta(39-121)$ has a dominant effect on Schwann cell proliferation. Although we prove that the wild-type schwannomin is present in the tumors, we found neither relocalization of a HA-tagged wild-type schwannomin coexpressed with the VSVtagged Sch- $\Delta(39-121)$ in HeLa cells, nor coimmunoprecipitation of Sch- $\Delta(39-121)$ and endogenous schwannomin in protein extracts of normal transgenic peripheral nerve and tumor tissues under the experimental conditions used by Scoles et al. (1998) (data not shown). Therefore, these results do not support a dominant-negative mechanism of Sch- $\Delta(39-121)$. This leaves open the possibility of interaction of Sch- $\Delta(39-121)$ with other proteins due to a conformational change leading to altered binding properties to membrane and intracellular components (Nishi et al. 1997; Deguen et al. 1998; Xu and Gutmann 1998). For this interaction, the carboxy-terminal domain is required, as overexpression of Sch- $\Delta$ Cter lacking this domain did not lead to tumorigenesis, although the mutant protein was detected at similar high levels when compared with Sch- $\Delta(39-121)$.

In humans, germ-line mutations predicted to generate carboxy-terminally truncated schwannomins have been generally associated with a more severe clinical outcome (Merel et al. 1995a; Parry et al. 1996; Ruttledge et al. 1996; Evans et al. 1998). Immunohistochemical studies examining tumor specimens have failed to identify such protein species (Stemmer-Rachamimov et al. 1997; Gutmann et al. 1998) suggesting that the severe phenotype is associated with the complete loss of NF2 function. Our observation that high expression of Sch- $\Delta$ Cter in the transgenic mice is associated neither with developmental abnormalities nor with tumorigenic effects indicates that in humans residual expression of carboxy-terminally truncated schwannomins would not be detrimental.

The less frequent exon-skipping mutations that leave the carboxy-terminal domain unaltered occur in both mildly and severely affected individuals. The NF2 transcript lacking exons 2 and 3 is one of a series of transcript isoforms generated by alternative splicing that are physiologically present at a low concentration in human leptomeningeal tissue and in human brain (Nishi et al. 1997). Nevertheless, the expression levels and physiologic relevance of the corresponding mutant proteins in normal tissues are so far unknown. Recently, Koga et al. (1998) have shown that the abnormal profiles found in 4 of 11 NF2-related tumors by protein truncation test (PTT) were due to the skipping of exon 2 (2 of 4), exon 3 (1 of 4) or exons 2-3 (1 of 4), but the expression level of the resulting mutant proteins in the tumors was not investigated. Precise evaluation of the relative levels of expression of the wild-type and mutant schwannomins 
resulting from in-frame exonic deletions will be mandatory to document the relevance of the present animal model to human NF2.

\section{Materials and methods}

\section{Construction of plasmids and transgenic mice}

Construction of plasmids containing mutant Sch- $\Delta$ Cter and Sch- $\Delta(39-121)$ isoforms has been described previously (Deguen et al. 1998). The 11 carboxy-terminal amino acids from the vesicular stomatitis virus (VSV) glycoprotein G, preceded by a proline-rich secondary structure breaker (GPPGP), were linked in-frame to the carboxyl terminus of the deletion mutants. The fusion protein is detectable with antibodies raised against either wild-type schwannomin or the tag corresponding to the carboxy-terminal end of the glycoprotein G. Plasmid pPG6 containing the $1.1 \mathrm{~kb}$ of P0 promoter linked onto the $\beta$-globin $3^{\prime}$ splicing and polyadenylation signals was provided by Dr. G. Lemke (Salk Institute, La Jolla, CA). An EcoRI fragment containing the VSV-tagged Sch- $\Delta$ Cter or Sch- $\Delta(39-121)$ cDNA was blunt-ended and subcloned into the EcoRV site of pPG6 to generate P0-Sch- $\Delta$ Cter and P0-Sch- $\Delta(39-121)$. Constructs were separated from the vector sequences by digestion with NotI and SalI followed by electroelution. Transgenic mice were generated by use of inbred FVB/N zygotes as described previously (Akagi et al. 1997). Tail genomic DNA was prepared and tested either by Southern blotting (founder mice) or PCR analysis (subsequent generations) with forward primers GAP3.3 [P0-Sch- $\Delta(39$ 121)] 5'-AGATACTGACATGAAGCGG-3' or GAP2.2 (P0-Sch-

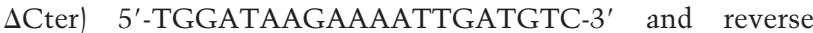
primer TAG.Anti: 5'-TTACTTGCCCAGCCGGTTCAT-3'. Breeding lines of animals were maintained by backcrosses to $\mathrm{FVB} / \mathrm{N}$ mice.

Western blot analysis of transgene expression in normal tissues from transgenic mice

Tissues and tumors from transgenic and nontransgenic littermates were frozen in liquid nitrogen and stored at $-70^{\circ} \mathrm{C}$ until further processing. Samples were homogenized in $8 \mathrm{M}$ of Urea in a Ultra-Turrax (IKA Labortechnik, Staufen, Germany), sonicated three times for $10 \mathrm{sec}$ each time and centrifuged at $10,000 \mathrm{~g}$ for $4 \mathrm{~min}$ at $4^{\circ} \mathrm{C}$. Protein concentration of the supernatant was assessed by Coomassie plus protein assay reagent (Pierce, Rockford, IL).Twenty micrograms of protein were denatured in Laemmli sample buffer by boiling for $3 \mathrm{~min}$ and analyzed on a reducing $8 \%$ SDS-polyacrylamide gel. Proteins were blotted to nitrocellulose membranes by electrotransfer. Blotted proteins were Ponceau-S (Bio-Rad, Hercules, CA) stained for visual confirmation of equal loadings. Membranes were blocked with $4 \%$ nonfat dry milk in PBS overnight at $4^{\circ} \mathrm{C}$. Blots were incubated with specific affinity-purified polyclonal rabbit antibody solutions anti-VSV-G (1:200; gift of Dr. M. Arpin, Institut Curie, Paris, France) or anti-NF2-Nter A-19 (0.5 $\mu \mathrm{g} / \mathrm{ml}$; Santa Cruz Biotechnology). Membranes were incubated with horseradish peroxidase-conjugated donkey anti-rabbit immunoglobulin secondary antibodies (Amersham) for $1 \mathrm{hr}$ at room temperature. Detection was performed by chemoluminescence (Boehringer-Mannheim).

\section{Immunoprecipitation and immunoblotting}

Samples were disrupted in RIPA buffer $[0.1 \%$ SDS, $0.5 \%$ deoxycholate, 1\% NP-40, $150 \mathrm{~mm} \mathrm{NaCl}, 50 \mathrm{~mm}$ Tris (pH 8)] contain- ing protease inhibitors (Complete tablets, Boehringer-Mannheim) in a Ultra-Turrax and lysed for $30 \mathrm{~min}$ on ice. Lysates were cleared by centrifugation at $7000 \mathrm{rpm}$ for $5 \mathrm{~min}$ at $4^{\circ} \mathrm{C}$. Protein concentration of the supernatant was assessed by Coomassie plus protein assay reagent (Pierce). A total of $0.5 \mathrm{mg}$ of protein extract was precleared by incubation with protein $\mathrm{A}-\mathrm{a}-$ garose beads (Sigma-Aldrich) for $1 \mathrm{hr}$ at $4^{\circ} \mathrm{C}$ on a rotating wheel, then incubated for $3 \mathrm{hr}$ at $4^{\circ} \mathrm{C}$ with $0.1 \mu \mathrm{g}$ of the rabbit polyclonal antibody anti-NF2-Cter C-18 (Santa Cruz Biotechnology), and with protein A-agarose beads. Immunoprecipitates were washed two times with $1 \mathrm{ml}$ of RIPA buffer and eluted in electrophoresis Laemmli sample buffer. Proteins were separated on a $8 \%$ polyacrylamide gel and blotted to nitrocellulose membranes by electrotransfer. The membrane was blocked overnight at $4{ }^{\circ} \mathrm{C}$ with TBST (Tris-buffered saline supplemented with $0.15 \%$ Tween 20 ) containing $5 \%$ nonfat dry milk and incubated for $2 \mathrm{hr}$ at room temperature with either affinity-purified rabbit polyclonal anti-NF2-Nter A-19 $(0.5 \mu \mathrm{g} / \mathrm{ml})$ or mouse monoclonal anti-VSV-G (12.5 $\mathrm{\mu g} / \mathrm{ml}$; Boehringer-Mannheim). Membranes were incubated for $1 \mathrm{hr}$ at room temperature with horseradish peroxidase-conjugated donkey anti-rabbit immunoglobulin secondary antibody (Amersham) or with horseradish peroxidase-conjugated sheep anti-mouse immunoglobulin secondary antibody (Amersham), where appropriate. Detection was performed by chemoluminescence (Boehringer-Mannheim).

\section{Histopathology}

Mice were sacrificed when moribund or held until 24 months of age. A complete necropsy was performed and tissues were fixed in formalin, paraffin embedded, sectioned at $5 \mu \mathrm{m}$, stained with hematoxylin and eosin and examined microscopically. After the brain was removed, the facial skeleton was decalcified, sectioned in the coronal plane, and embedded in toto. Multiple longitudinal sections of the vertebral column were also examined.

\section{Immunohistochemistry}

Paraffin sections of tumors were deparaffinized and rehydrated. All immune reactions were preceded by a blocking step in protein block serum free solution (DAKO) and were carried out at $4{ }^{\circ} \mathrm{C}$ overnight. The following rabbit polyclonal antisera were used: anti-bovine S-100 protein (DAKO), anti-mouse p75 LNGFR (Chemicon International, Temecula, CA). Secondary antibodies were affinity-purified goat anti-rabbit HRP-conjugated (horseradish peroxidase-labeled goat anti-rabbit IgG, Amersham), and visualized with DAB substrate. Sections were counterstained by aqueous hematoxylin (Zymed, South San Francisco, CA).

\section{FISH on paraffin embedded tumor material}

FISH was performed with biotin-labeled mouse chromosome 11-specific DNA probe (Oncor, Gaithersburg, MD). The sections for hybridization were deparaffinized in a xylene and alcohol series and air-dried. To ensure good penetration of the probes into the nuclei, the sections were pretreated with sodium thiocyanate $(1 \mathrm{M})$ for $30 \mathrm{~min}$ at $80^{\circ} \mathrm{C}$. After washing in distilled water, the sections were immediately incubated in pepsin solution $(4.0 \mathrm{mg} / \mathrm{ml}$ in $0.2 \mathrm{~N} \mathrm{HCl})$ for $20 \mathrm{~min}$ at $37^{\circ} \mathrm{C}$, rinsed in PBS, fixed in phosphate-buffered formaldehyde $3.8 \%$ solution for $10 \mathrm{~min}$ at room temperature, and air-dried. Probe and target DNA were denatured at $75^{\circ} \mathrm{C}$ on a heating plate for $10 \mathrm{~min}$ and hybridization was performed at $37^{\circ} \mathrm{C}$ for $16-20 \mathrm{hr}$. Posthybridization washes and visualization of the probes were performed 
as described previously (Giovannini et al. 1992). For each tumor, 50-100 nuclei showing a clear hybridization signal were evaluated for copy number of chromosome 11 . The following criteria described by Hopman et al. (1991) were used in evaluating FISH signals: (1) Overlapping nuclei were not analyzed; (2) the signals in one nucleus had to be of uniform size and intensity; (3) paired (split) signals were counted as one signal; and (4) unspecific signals of minor binding sites were not counted.

\section{Acknowledgments}

We thank G. Lemke for plasmid DNA; K. van Veen-Buurman, and R. Bobeldijk for zygote injections; F. van der Ahé, K. Ankama, N. Bosnie, H. Raasø, L. Rijswijk, A. Zwerver, and L. Aussepé for animal care; R. Regnerus, B. Thuille, L. Lelievre, and V. Abramowski for genotypic analysis; J. Bulthuis, K. de Goeij, D. Hoogervorst, L. Kuijper-Pietersma, and E. van Muylwijk for histotechnical assistance; $M$. Arpin for polyclonal antiVSV-G antibodies; A. Janin, J. Mahler, and J. Poirier for discussion of the pathological phenotypes; B. Deguen for sharing unpublished results; P. Laurent-Puig for statistical analysis; G. Linares-Cruz, M. Busson-Le Coniat, and R. Berger for help and advice in the FISH experiments. This work was supported by Grants from the European Commission (BMH-CT96-1518), Ligue Nationale Française Contre le Cancer, Association pour la Recherche sur le Cancer, and by postdoctoral fellowships from Human Frontier Science Program (M.G.); ECC (M.G.; E.R.-M.); European Molecular Biology Organization (EMBO; M.G.), and INSERM (M.N.-K.). INSERM U434 is laboratoire associé n.4 of the Comité de Paris de la Ligue Nationale Contre le Cancer.

The publication costs of this article were defrayed in part by payment of page charges. This article must therefore be hereby marked 'advertisement' in accordance with 18 USC section 1734 solely to indicate this fact.

\section{References}

Akagi, K., V. Sandig, M. Vooijs, M. Van der Valk, M. Giovannini, M. Strauss, and A. Berns. 1997. Cre-mediated somatic site-specific recombination in mice. Nucleic Acids Res. 25: $1766-1773$.

Bianchi, A.B., T. Hara, V. Ramesh, J. Gao, A.J. Klein-Szanto, F. Morin, A.G. Menon, J.A. Trofatter, J.F. Gusella, B.R. Seizinger, and N. Kley. 1994. Mutations in transcript isoforms of the neurofibromatosis 2 gene in multiple human tumour types. Nat. Genet. 6: 185-192.

Bijlsma, E.K., P. Merel, D.A. Bosch, A. Westerveld, O. Delattre, G. Thomas, and T.J. Hulsebos. 1994. Analysis of mutations in the $\mathrm{SCH}$ gene in schwannomas. Genes Chromosomes Cancer 11: 7-14.

Deguen, B., P. Merel, L. Goutebroze, M. Giovannini, H. Reggio, M. Arpin, and G. Thomas. 1998. Impaired interaction of naturally occurring mutant NF2 protein with actin-based cytoskeleton and membrane. Hum. Mol. Genet. 7: 217-226.

Eldridge, R. 1981. Central neurofibromatosis with bilateral acoustic neuroma. Adv. Neurol. 29: 57-65.

Evans, D.G., L. Trueman, A. Wallace, S. Collins, and T. Strachan. 1998. Genotype/phenotype correlations in type 2 neurofibromatosis (NF2): Evidence for more severe disease associated with truncating mutations. I. Med. Genet. 35: 450455.

Giovannini, M., L. Selleri, J.A. Biegel, K. Scotlandi, B.S. Emanuel, and G.A. Evans. 1992. Interphase cytogenetics for the detection of the $\mathrm{t}(11 ; 22)(\mathrm{q} 24 ; \mathrm{q} 12)$ in small round cell tu- mors. J. Clin. Invest. 90: 1911-1918.

Gutmann, D.H., R.T. Geist, H. Xu, J.S. Kim, and S. SaporitoIrwin. 1998. Defects in neurofibromatosis 2 protein function can arise at multiple levels. Hum. Mol. Genet. 7: 335-345.

Hopman, A.H., E. van Hooren, C.A. van de Kaa, P.G. Vooijs, and F.C. Ramaekers. 1991. Detection of numerical chromosome aberrations using in situ hybridization in paraffin sections of routinely processed bladder cancers. Mod. Pathol. 4: 503513.

Hoshi, N., H. Hiraki, T. Yamaki, T. Natsume, K. Watanabe, and T. Suzuki. 1994. Frequent expression of $75 \mathrm{kDa}$ nerve growth factor receptor and phosphotyrosine in human peripheral nerve tumours: An immunohistochemical study on paraffinembedded tissues. Virchows Arch. 424: 563-568.

Houdeau, E., A. Rousseau, C. Meusnier, M.J. Prud'Homme, and J.P. Rousseau. 1998. Sympathetic innervation of the upper and lower regions of the uterus and cervix in the rat have different origins and routes. J. Comp. Neurol. 399: 403-412.

Jacoby, L.B., M. MacCollin, R. Barone, V. Ramesh, and J.F. Gusella. 1996. Frequency and distribution of NF2 mutations in schwannomas. Genes Chromosomes Cancer 17: 45-55.

Koga, H., N. Araki, H. Takeshima, T. Nishi, T. Hirota, Y. Kimura, M. Nakao, and H. Saya. 1998. Impairment of cell adhesion by expression of the mutant neurofibromatosis type 2 (NF2) genes which lack exons in the ERM- homology domain. Oncogene 17: 801-810.

Kreis, T.E. 1986. Microinjected antibodies against the cytoplasmic domain of vesicular stomatitis virus glycoprotein block its transport to the cell surface. EMBO I. 5: 931-941.

LaJeunesse, D.R., B.M. McCartney, and R.G. Fehon. 1998. Structural analysis of Drosophila merlin reveals functional domains important for growth control and subcellular localization. J. Cell Biol. 141: 1589-1599.

Luongo, C., A.R. Moser, S. Gledhill, and W.F. Dove. 1994. Loss of Apc+ in intestinal adenomas from Min mice. Cancer Res. 54: 5947-5952.

McClatchey, A.I., I. Saotome, K. Mercer, D. Crowley, J.F. Gusella, R.T. Bronson, and T. Jacks. 1998. Mice heterozygous for a mutation at the Nf2 tumor suppressor locus develop a range of highly metastatic tumors. Genes \& Dev. 12: 1121-1133.

Mahler, J.F., W. Stokes, P.C. Mann, M. Takaoka, and R.R. Maronpot. 1996. Spontaneous lesions in aging $\mathrm{FVB} / \mathrm{N}$ mice. Toxicol. Pathol. 24: 710-716.

Merel, P., H.X. Khe, M. Sanson, E. Bijlsma, G. Rouleau, P. Laurent-Puig, S. Pulst, M. Baser, G. Lenoir, J.M. Sterkers, J. Philippon, F. Resche, V.F. Mautner, G. Fischer, T. Hulsebos, A. Aurias, O. Delattre, and G. Thomas. 1995a. Screening for germ-line mutations in the NF2 gene. Genes Chromosomes Cancer 12: 117-127.

Merel, P., K. Haong-Xuan, M. Sanson, A. Moreau-Aubry, E.K. Bijlsma, C. Lazaro, J.P. Moisan, F. Resche, I. Nishisho, X. Estivill, J.Y. Delattre, M. Poisson, C. Theillet, T. Hulsebos, O. Delattre, and G. Thomas. 1995b. Predominant occurrence of somatic mutations of the NF2 gene in meningiomas and schwannomas. Genes Chromosomes Cancer 13: 211-216.

Messing, A., R.R. Behringer, J.P. Hammang, R.D. Palmiter, R.L. Brinster, and G. Lemke. 1992. P0 promoter directs expression of reporter and toxin genes to Schwann cells of transgenic mice. Neuron 8: 507-520.

Moscarini, M., A. Cantagalli, C. Cavallotti, C. De Luca, and F. Amenta. 1982. Cholinergic nerves in mouse uterus. J. Neural Transm. 55: 139-148.

Nigro, J.M., S.J. Baker, A.C. Preisinger, J.M. Jessup, R. Hostetter, K. Cleary, S.H. Bigner, N. Davidson, S. Baylin, P. Devilee, T. Glover, F.S. Collins, A. Weston, R. Modali, C.H. Harris, and 
B. Vogelstein. 1989. Mutations in the $p 53$ gene occur in diverse human tumour types. Nature 342: 705-708.

Nishi, T., H. Takeshima, K. Hamada, K. Yoshizato, H. Koga, K. Sato, K. Yamamoto, I. Kitamura, M. Kochi, J.-I. Kuratsu, H. Saya, and Y. Ushio. 1997. Neurofibromatosis 2 gene has novel alternative splicings which control intracellular protein binding. Int. J. Oncol. 10: 1025-1029.

Parry, D.M., M.M. MacCollin, M.I. Kaiser-Kupfer, K. Pulaski, H.S. Nicholson, M. Bolesta, R. Eldridge, and J.F. Gusella. 1996. Germ-line mutations in the neurofibromatosis 2 gene: correlations with disease severity and retinal abnormalities. Am. J. Hum. Genet. 59: 529-539.

Perosio, P.M. and J.J. Brooks. 1988. Expression of nerve growth factor receptor in paraffin-embedded soft tissue tumors. Am. J. Pathol. 132: 152-160.

Rouleau, G.A., P. Merel, M. Lutchman, M. Sanson, J. Zucman, C. Marineau, K. Hoang-Xuan, S. Demczuk, C. Desmaze, B. Plougastel, S.M. Pulst, G. Lenoir, E. Bijlsma, R. Fashold, J. Dumanski, P. de Jong, D. Parry, R. Eldridge, A. Aurias, O. Delattre, and G. Thomas. 1993. Alteration in a new gene encoding a putative membrane-organizing protein causes neuro-fibromatosis type 2. Nature 363: 515-521.

Ruttledge, M.H., A.A. Andermann, C.M. Phelan, J.O. Claudio, F.Y. Han, N. Chretien, S. Rangaratnam, M. MacCollin, P. Short, D. Parry, V. Michels, V.M. Riccardi, R. Weksberg, K. Kitamura, J.M. Bradburn, B.D. Hall, P. Propping, and G.A. Rouleau. 1996. Type of mutation in the neurofibromatosis type 2 gene (NF2) frequently determines severity of disease. Am. J. Hum. Genet. 59: 331-342.

Sainz, J., D.P. Huynh, K. Figueroa, N.K. Ragge, M.E. Baser, and S.M. Pulst. 1994. Mutations of the neurofibromatosis type 2 gene and lack of the gene product in vestibular schwannomas. Hum. Mol. Genet. 3: 885-891.

Scoles, D.R., D.P. Huynh, P.A. Morcos, E.R. Coulsell, N.G. Robinson, F. Tamanoi, and S.M. Pulst. 1998. Neurofibromatosis 2 tumour suppressor schwannomin interacts with $\beta I I-$ spectrin. Nat. Genet. 18: 354-359.

Shaw, R.J., A.I. McClatchey, and T. Jacks. 1998a. Localization and functional domains of the neurofibromatosis type II tumor suppressor, merlin. Cell Growth Differ. 9: 287-296.

- 1998b. Regulation of the neurofibromatosis type 2 tumor suppressor protein, merlin, by adhesion and growth arrest stimuli. J. Biol. Chem. 273: 7757-7764.

Sherman, L., H.M. Xu, R.T. Geist, S. Saporito-Irwin, N. Howells, H. Ponta, P. Herrlich, and D.H. Gutmann. 1997. Interdomain binding mediates tumor growth suppression by the NF2 gene product. Oncogene 15: 2505-2509.

Stemmer-Rachamimov, A.O., L. Xu, C. Gonzalez-Agosti, J.A. Burwick, D. Pinney, R. Beauchamp, L.B. Jacoby, J.F. Gusella, V. Ramesh, and D.N. Louis. 1997. Universal absence of merlin, but not other ERM family members, in schwannomas. Am. J. Pathol. 151: 1649-1654.

Trofatter, J.A., M.M. MacCollin, J.L. Rutter, J.R. Murrell, M.P. Duyao, D.M. Parry, R. Eldridge, N. Kley, A.G. Menon, K. Pulaski, V.H. Haase, C.M. Ambrose, D. Munroe, C. Bove, J.L. Haines, R.L. Martuza, M.E. MacDonald, B.R. Seizinger, M.P. Short, A.J. Buckler, and J.F. Gusella. 1993. A novel moesin-, ezrin-, radixin-like gene is a candidate for the neurofibromatosis 2 tumor suppressor. Cell 72: 791-800.

Twist, E.C., M.H. Ruttledge, M. Rousseau, M. Sanson, L. Papi, P. Merel, O. Delattre, G. Thomas, and G.A. Rouleau. 1994. The neurofibromatosis type 2 gene is inactivated in schwannomas. Hum. Mol. Genet. 3: 147-151.

Walker, V.E., K.T. Morgan, H.M. Zimmerman, and J.R. Innes. 1994. Tumours of the central and peripheral nervous system. In Pathology of tumors in laboratory animals: Tumors of the mouse (ed. V. Turusov and U. Mohr), pp. 731-776. International Agency for Research on Cancer Scientific Publication, Lyon, France.

Wiestler, O.D. and H. Radner. 1994. Pathology of neurofibromatosis 1 and 2. In The neurofibromatoses. A pathogenetic and clinical overview (ed. S.M. Huson and R.A. C. Hughes), pp. 135-159. Chapman \& Hall, London, UK.

Xu, H.M. and D.H. Gutmann. 1998. Merlin differentially associates with the microtubule and actin cytoskeleton. I. Neurosci. Res. 51: 403-415.

Xu, L., C. Gonzalez-Agosti, R. Beauchamp, D. Pinney, C. Sterner, and V. Ramesh. 1998. Analysis of molecular domains of epitope-tagged merlin isoforms in Cos- 7 cells and primary rat Schwann cells. Exp. Cell Res. 238: 231-240.

Zorick, T.S. and G. Lemke. 1996. Schwann cell differentiation. Curr. Opin. Cell Biol. 8: 870-876. 


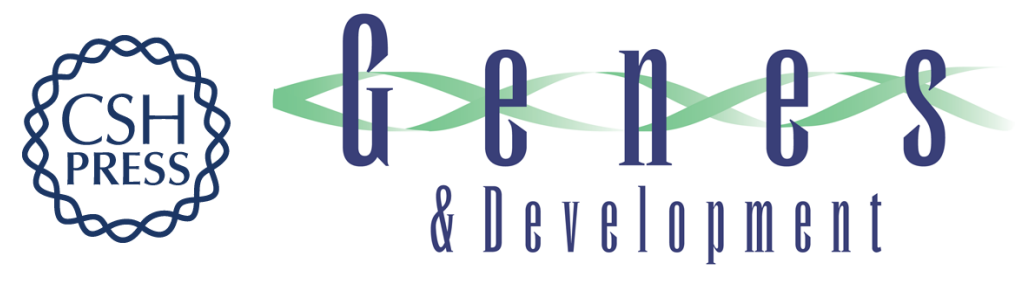

\section{Schwann cell hyperplasia and tumors in transgenic mice expressing a naturally occurring mutant NF2 protein}

Marco Giovannini, Els Robanus-Maandag, Michiko Niwa-Kawakita, et al.

Genes Dev. 1999, 13:

References This article cites 38 articles, 6 of which can be accessed free at: http://genesdev.cshlp.org/content/13/8/978.full.html\#ref-list-1

License

Email Alerting

Receive free email alerts when new articles cite this article - sign up in the box at the top Service right corner of the article or click here.

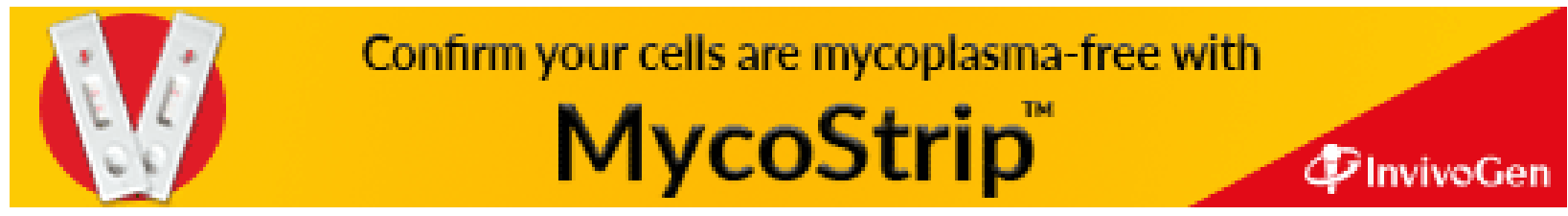

